\title{
Solving Production Processes Disparity Issue through Implementation of Poka-Yoke Concept
}

\author{
Che-Ani M. N., Sapian A. S., Azid I. A., and Kamaruddin S.
}

\begin{abstract}
The concept of zero defects is remarkable for its simplicity and directness. One of the concepts of zero defects is poka-yoke, which means "mistake-proofing". Its purpose is to eliminate product defects by preventing, correcting, or drawing attention to human errors as they occur. The primary goal of this paper is to focus on the improvement of the quality issue in production processes by identifying and implementing poka-yoke concept to improve the defects. In this paper, the quality tools such as Pareto diagram and Ishikawa diagram were applied to obtain the possible root causes of the quality issue and solving the issue by poka-yoke concept. The result shows that through implementing the poka-yoke concept, the quality has improved and this will ultimately ensure the economic benefits to the company.
\end{abstract}

Index Terms-Quality, zero defects, poka-yoke, quality tools.

\section{INTRODUCTION}

Quality is a term that carries important meaning to both producer and customer in market. In the global marketplace today, many organizations realized that its survival in the business world depends highly on producing high quality product and services. Indeed, a lot of organizations have emphasized that quality should have to be put in place, integrated within the management system, especially in terms of bringing the end products or services to the customers. Accordingly, Total Quality Management (TQM) has become increasingly prevalent as one of the management strategies in ensuring customer satisfaction and loyalty, improving products and service quality and reinforcing continuous improvement [1]. There are many roads to quality, each of which is represented by methodologies that attempt to encapsulate complex theories in simplified forms. But a process without defect doesn't just happen. Performing task right the first time only works if it can be done right the next time.

Six Sigma is a tool in the automotive industry to improve quality of processes. Six Sigma can be considered a business strategy and a science that has the aim of reducing manufacturing and service cost, and creating significant improvement in customer satisfaction and bottom-line saving through combining statistical and business process methodologies into an integrated model of process, product

Manuscript received May 18, 2016; revised August 5, 2016

Che-Ani M. N., Sapian A. S., and Azid I. A. are with Universiti Kuala Lumpur, Malaysia (e-mail: mnorzaimi@unikl.edu.my, ahmadsaufi1992@yahoo.com, Ishak.abdulazid@unikl.edu.my).

Kamaruddin S. is with the Mechanical Department, Universiti Teknologi Petronas, Malaysia (e-mail: shahrul.k@ petronas.com.my). and service. In Six Sigma and using the DMAIC model, the purposes of process improvement are to increase performance and decrease in performance variability. This increase in performance and decrease in performance variation will lead to defect reduction and improvement in profits, to employee morale, and quality of product and eventually to business excellence.

Abidin et al. [2] had conducted the study about Design Capabilities Development for Malaysian Vendors in Automotive Industry and they found that the critical success factor for quality improvement such as proximity is important for accuracy of the data analysis and integration. TQM would be one of the measurements to ensure that the automotive components produced are satisfactory and reliable for the customers, and to ensure competitiveness in the market, as well as in accordance with to the international standard. The TQM concept by using quality tools which is adopted from six sigma methodology and concept of poka-yoke will be adopted for this research, which uses a quality tools such as Pareto diagram, Ishikawa diagram and poka-yoke concept to complete the research. A quality improvement model is based on achieving zero defects where the whole quality process is an attitude towards a performance standard [3]-[7]. With a zero defect mind-set, each defect is rigorously traced to its root cause, and each cause is then will be prevented [8]-[11].

Continuous improvement by implementation of Zero Defects concept is a management tool that aim to reduce defects through mistake prevention. It is directed at motivating people or employer to prevent mistakes by developing a conscious desire to do their job right the first time. Thus, the proposed research will eventually leads to proper approach for achieving zero defects in the car assembly manufacturer in Malaysia. The research presented in this paper had been conducted through problem solving activities of the product quality by identifying and adopting the effective suitable tools for the poka-yoke concept.

\section{The Case Study And Problem Statement}

The case study company is an automotive assembly process which involves final assembly of the vehicle manufacturing. The layout of the production shop floor consists of single production assembly line and is divided into four main section which are trim, chassis, final assembly and final inspection. The process is sequential, in batch, multi-path and asynchronous. Each process is managed by difference group of management and it influences the reject rate due to disparity issue such as miscommunication. The reject rate has been monitored within a month in the Final Inspection process and the data has been analyzed, and the solution to reduce the 
part defects needs to be found.

The main issue for this company is the quality issue which consists of several types of defects. Based on this historical data, the Pareto diagram has been applied to determine the main defects and priorities, and the selected issue to be solved. Pareto diagram has been used to define the main motion wastes in the bottleneck process. The application of the Pareto diagram because of the diagram will graphically shows the main problem in some situation and also based on the 80/20 rule. The $80 / 20$ Rule means that in anything a few (20 percent) are vital and many ( 80 percent) are trivial. In Juran's initial work, he identified 20 percent of the defects causing 80 percent of the problems. From the Pareto diagram, the Ishikawa diagram (or cause and effects diagram) was applied to brainstorming the possible root causes of the wastes. This can set the priorities for many practical problems as faced by the industries particularly when carrying out the defects. Besides, through the charting mechanism it can show the weight how much effort to be ratified which resulting into better use of limited resources.

Based on the observed attributed data, the type of defects can be divided into eight main categories which are broken $(35 \%)$, bend $(30 \%)$, trip loose $(10 \%)$, bolt broken $(5 \%)$, scratch $(5 \%)$, crack $(5 \%)$, wrinkle $(5 \%)$ and others $(5 \%)$. From the information and the data collection, the Pareto chart is plotted to visualize the quantity and type of defects as shown in Fig. 1.

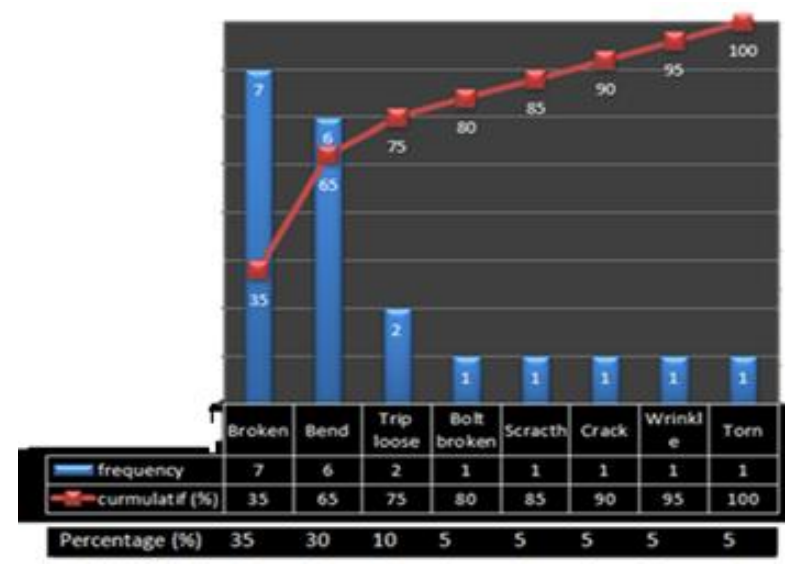

Fig. 1. The Pareto chart for total defects.

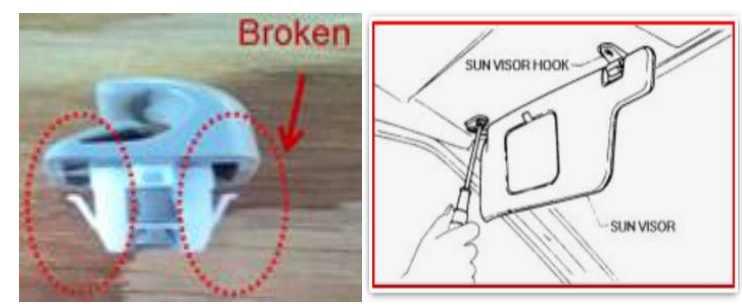

Fig. 2. The broken part.

Since the broken is a highest contributed for the reject rate, it was selected to solve by using poka-yoke concept. The broken refer to the hook which is the part that is connected to portion of sun visor to the car body. Hook sun visor is commonly made from plastic and the part is usually assembled by only using clip. Based on the study of the line production, the hook sun visor was broken because the part was wrong installed during the assembly processes. The broken happened when the worker applied some forces to dismantle the wrong assembly part as shown in Fig. 2.

\section{RESULTS AND DISCUSSION}

Once the major contribution of the issues is identified through the Pareto chart, the Ishikawa diagram is the used as a guideline during a brainstorming session. The brainstorming session using Ishikawa diagram involves all the workers related with the process, to ensure all possible root causes will be recorded based on the four factors which are man, method, material and machine. The Ishikawa diagram can also allow the possible causes or problem to be identified structurally and can also determine the relationships among potential causes of defects.

Ishikawa Diagram was applied as a guideline during a brainstorming session to brainstorm the possible root causes of the high cycle time of the adjustment process. The brainstorming session consisted of cross-functional team members from almost all departments related with the product such as Production Department, Engineering Department, Quality Assurance, Maintenance Department, Supplier Quality Management and Training Department. This brainstorming session focused on the four major factors which were manpower, method, material and machine or also known as a 4M. All the problems occurred must be classified based on these factors. All the possible root causes raised by team members were plotted into Ishikawa Diagram based on the classification of the each factor; with the arising issues must have a mutual concession from the majority of the team members.

Classification of the issues depending on the all four factors where; firstly Manpower is all the issues related with the skills, experiences, competency, attitude and condition of the workers or any issue related with the personal issue of the worker. Secondly, Method is related to the procedure performing the tasks such as technique, approach, routine and manner to assemble the part. Thirdly, the Material covers all issues related to all type of raw material, either from suppliers or in-house preparation. Fourthly, the Machine is classified anything about performing, designing, downtime, or anything about the machine issues.

The Ishikawa diagram is obtained from the brainstorming session among team members to find the possible root-causes of the defects. The failure of the hook was investigated to find the possible root-causes by using an Ishikawa diagram. The Ishikawa diagram for the broken hook is shown in Fig. 3.

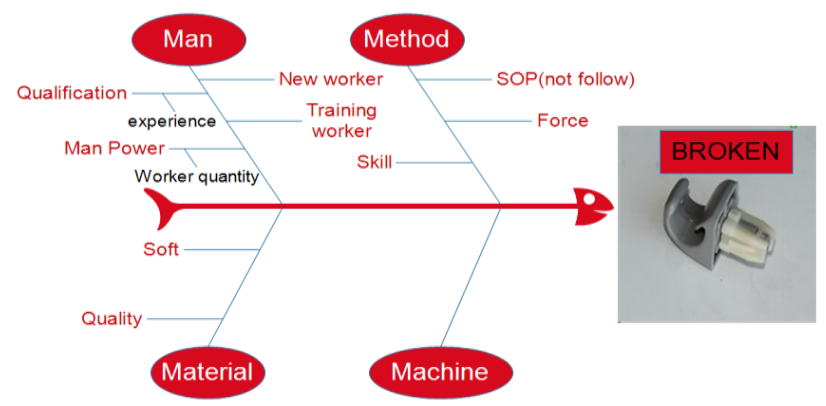

Fig. 3. The Ishikawa diagram.

Based on the brainstorming session from the Ishikawa 
diagram, the team members agreed the broken hook happened due to soften part and the similarity of the size of the part designed from left or right view. The wrong assembly was due to the process was human dependent. Currently, the component legs of the part were designed very similar and very hard to differentiate for both sides. A chance for the wrong assemble is high because human depending and worker need to inspect and ensure the orientation of the component leg are in right path. Wrong path means the defect will be arise and rework process are needed.

To solve the problem, the part was redesigned by using poka-yoke concept or also known as a mistake proofing concept to solve the quality issue. The aim of Poka-yoke is to eliminate defects in a product by preventing or correcting mistakes as early as possible. The component leg of the part was designed based on difference size for both sides to ensure the assembly of the part from one direction only as shown in Fig. 4. By designing difference sizes, the worker are easily visualize and detect the direction of the part assembly. If the hook is assembled from the opposite direction, the process will be unsmooth and worker immediately detect the wrong assembly part. Furthermore, to ensure the process improvement is smooth, the visual management concept was introduced which is using color coding technique. The left side of the component leg was occupied by yellow sticker to ensure the assembly process is correct direction. The color coding has been applied to avoid from the wrong assembly direction as shown in Fig. 5.

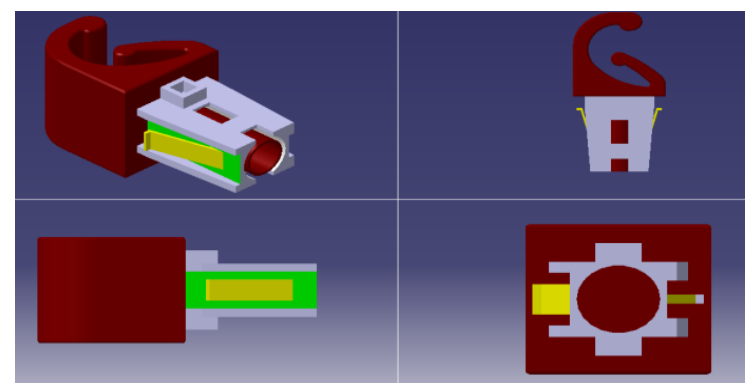

Fig. 4 Poka-yoke for geometry of the part.

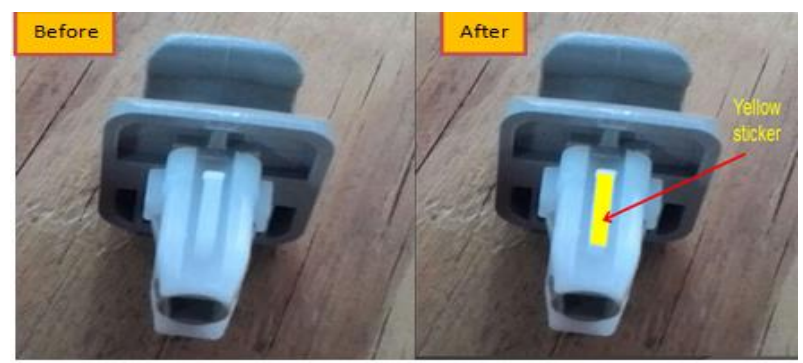

Fig. 5. Color coding of the part.

In overall improvement activities, two simple improvement techniques were introduced to solve the problem of defects in production assembly area. Small changes cause the improvement of the product quality and at the same time improving the productivity, reducing the operation costs and improving the morale of employees.

\section{CONCLUSION}

The ever increasing expectation in manufacturing industry has made continuous improvement activities are necessary for the cost reduction purposes. The main aspect in any manufacturing industry generally is to increase the customer expectation is eliminating the defects and reducing the variances. The defects must be defined properly to ensure the root causes will be eliminating once the process improvement has been identified. In the manufacturing process, the defect means during process assembly, the improper assembled of the party occurs. Due to this defect, the worker may need to continue the adjustment in the production process that meets the desired requirements. Further processes due to defect can be divided into two categories which are rework or scrap. Rework means the part will be dismantling and re-assembly again to meet customer specification. The time and cost spent during repairing the defect will affect the productivity activity production line. While, the scrap means the part is totally loss and no chance for the repairing process and company will me losing the investment and the beginning either direct or indirect cost. Based on this research, the result shows that the poka-yoke concept from quality improvement technique was able to reduce the defect. With the small investment, the continuous improvement will be carrying out immediately. The overall result also shows the significant improvement has been achieved which is the high reject of "broken" in production line was reduced $100 \%$ after the implementation of suggested poka-yoke concept. The poka-yoke concept has successfully eliminated the problem of "broken" and it improves the communication between the processes of assembly and at the same time meeting customer expectation.

\section{ACKNOWLEDGMENT}

This paper was fully supported by finance from Short Term Research Grant (STRG) with reference number STR15129 from Universiti Kuala Lumpur (UniKL). Also, appreciation is extended to the selected case study industry and anonymous reviewers for the comments given which lead to the significantly improved manuscript quality.

\section{REFERENCES}

[1] I. Osman, H. Ali, W. E. W. Rashid, and J. Kamauzaman, "Total quality management in the malaysian automobile industry," International Business Research, vol. 2, no. 1, February 2009.

[2] A. S. Z. Abidin, R. M. Yusuff, and R. Muslimen, "Exploratory study: Design capabilities development for malaysian vendors in automotive industry," presented at the 2011 International Conference on Industrial Engineering and Operations Management, 2011.

[3] J. P. Zimmerman and J. Weiss, "Six sigma's seven deadly sins," Quality, vol. 44, no. 1, 2005.

[4] A. Bhanpurkar, A. Bangar, S. Goyal, and P. Agrawal, "Implementation of Six Sigma Program for Lean Manufacturing To reduce the rework waste in transformer manufacturing unit by eliminating defect of leakage from bushings in oil filled transformers," International Journal of Mechanical and Industrial Engineering, no. 2231-6477, 2012.

[5] C. J. Lin, F. F. Chen, H. D. Wan, Y. M. Chen, and G. Kuriger, "Continuous improvement of knowledge management systems using Six Sigma methodology," Robotics and Computer Integrated Manufacturing, 2012.

[6] C. S. C. Kumar, N. V. R. Naidu, and K. Ravindranath, "Performance improvement of manufacturing industry by reducing the defectives using six Sigma methodologies," Journal of Engineering, vol. 1, issue 1, pp. 1-9, 2012.

[7] J. de Mast and J. Lokkerbol, "An analysis of the six Sigma DMAIC method from the perspective of problem solving," Int. J. Production Economics, vol. 139, pp. 604-614, 2012. 
[8] M. Soković, D. Pavletić, and E. Krulčić, "Six Sigma process improvements in automotive parts production," Journal of Achievements in Materials and Manufacturing Engineering, vol. 19, issue 1, pp. 96-102, 2006

[9] F. Johannsen and S. Leist, "A six Sigma approach for integrated solutions," Managing Service Quality, vol. 19, issue 5, pp. 558-580, 2009.

[10] D. Bratić, "Six Sigma: A key driver for process improvement," Communications of the IBIMA, 2011.

[11] P. A. Jenica, G. Mihai, and A. Sorin, "Using lean six Sigma as a motivational tool for processes improvement," The Journal of the Faculty of Economics, issue 2, pp. 438-442, 2011.

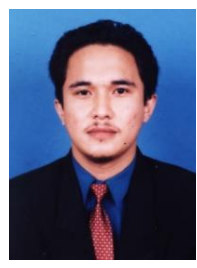

Che-Ani M. N. is PhD candidate of Manufacturing Engineering Section at the Universiti Kuala Lumpur Malaysian Spanish Institute. He earned the B.Eng. in mechanical engineering (industrial engineering) and masters in industrial engineering from Universiti Teknologi Malaysia, Malaysia. He is actively involved in research on process improvement in industry. His research interests include manufacturing engineering, industrial engineering, lean manufacturing, and quality engineering. He has completed various research projects with various industries focusing on lean manufacturing and six sigma programs.

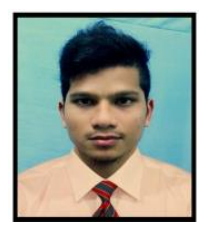

Sapian A. S. is bachelor degree student of Manufacturing Engineering Section at the Universiti Kuala Lumpur - Malaysian Spanish Institute. His research interests include manufacturing engineering, and quality engineering.

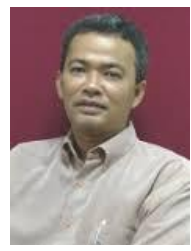

Azid A. I. is a Professor of Mechanical Section at the Universiti Kuala Lumpur Malaysian Spanish Institute, Kulim, Kedah, Malaysia. Ishak Abdul Azid received the B.Sc. degree in mechanical engineering from Clarkson University, Potsdam, NY, in 1992, the M.Sc. degree from University of Wales, Swansea, UK, in 1995, and the $\mathrm{Ph} . \mathrm{D}$. degree from University of Wales, Cardiff, UK, in 1999. He is currently a Professor at the School of Mechanical Engineering, Universiti Sains Malaysia, Penang, Malaysia. He has published more than 100 papers in journals and conferences. He has various experiences in manufacturing industries especially in the field of optimization in industrial engineering. His research interests include application of artificial intelligence in industrial engineering, micro electromechanical systems (MEMS) and thermal management in electronic packaging.

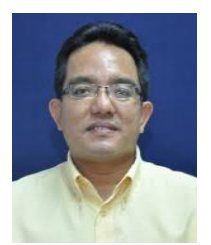

Kamarudin S. is an Associate Professor of Mechanical Engineering Department at the Universiti Teknologi Petronas. Shahrul Kamaruddin received the BEng(Hons) degree from University of Strathclyde, Glasgow, Scotland in 1996, the M.Sc. degree from University of Birmingham, U.K., in 1998, and the $\mathrm{PhD}$ from University of Birmingham, in 2003. He has various past experiences with manufacturing industries from heavy to electronics industries especially in the field of industrial engineering, manufacturing processes and product design. He has more than 100 publications in reputed international and national journals/conferences. His current research interests include simulation and modelling of manufacturing systems, production planning and control, maintenance management and manufacturing processes. 